\title{
A New Method for Seismically Safe Managing of Seismotectonic Deformations in Fault Zones
}

\author{
Valery V. Ruzhich and Evgeny V. Shilko
}

\begin{abstract}
The authors outline the results of long-term interdisciplinary research aimed at identifying the possibility and the methods of controlling tangential displacements in seismically dangerous faults to reduce the seismic risk of potential earthquakes. The studies include full-scale physical and numerical modeling of $\mathrm{P}-\mathrm{T}$ conditions in the earth's crust contributing to the initiation of displacement in the stick-slip regime and associated seismic radiation. A cooperation of specialists in physical mesomechanics, seismogeology, geomechanics, and tribology made it possible to combine and generalize data on the mechanisms for the formation of the sources of dangerous earthquakes in the highly stressed segments of faults. We consider the prospect of man-caused actions on the deep horizons of fault zones using powerful shocks or vibrations in combination with injecting aqueous solutions through deep wells to manage the slip mode. We show that such actions contribute to a decrease in the coseismic slip velocity in the fault zone, and, therefore, cause a decrease in the amplitude and energy of seismic vibrations. In conclusion, we substantiate the efficiency of the use of combined impacts on potentially seismically hazardous segments of fault zones identified in the medium-term seismic prognosis. Finally, we discuss the importance of the full-scale validation of the proposed approach to managing the displacement regime in highly-stressed segments of fault zones. Validation should be based on large-scale tests involving advanced technologies for drilling deep multidirectional wells, injection of complex fluids, and localized vibrational or pulse impacts on deep horizons.
\end{abstract}

Keywords Seismically active fault $\cdot$ Earthquake $\cdot$ Friction $\cdot$ Healing $\cdot$ Field experiment $\cdot$ Vibro-pulse impact $\cdot$ Deep drilling $\cdot$ Fluid injection $\cdot$ Shear stress relaxation $\cdot$ Slip control

\footnotetext{
V. V. Ruzhich ( $₫)$

Institute of the Earth's Crust, SB RAS, 664033 Irkutsk, Russia

e-mail: ruzhich@crust.irk.ru

E. V. Shilko

Institute of Strength Physics and Materials Science, SB RAS, 634055 Tomsk, Russia

e-mail: shilko@ispms.tsc.ru
} 


\section{Introduction}

The methods developed by the world community for countering natural seismic disasters are insufficient since they do not allow an efficient reduction of the almost annual losses caused by strong earthquakes [1-3]. To date, one has come to understand that difficulties in finding solutions to this problem are concerned with the lack of reliable information on the deep tribophysical and geochemical characteristics of earthquake preparation processes in fault zones. These geological processes are hidden at inaccessible seismic focal depths of the lithosphere (7-30 km) and occur at elevated temperatures and pressures of hundreds of megapascals. An important role in the preparation of earthquakes belongs to the migration of fluids of various compositions $[4,5]$. The results of a long- and medium-term prognosis make it possible to identify foci with indications of the final stage of the preparation of strong earthquakes with a probability of the order of $P=0.6-0.7$. In most cases, these are the same segments of the zones of interplate and intracontinental seismic faults, where "hot spots" of dangerous or catastrophic events have already arisen for many tens or hundreds of thousands of years. The modern possibilities of making a short-term forecast of strong and catastrophic earthquakes are still limited. Moreover, such a forecast cannot efficiently ensure seismic safety, since it does not prevent the large-scale negative consequences of destruction [6]. The world scientific community recognizes the need to search for new ways to more reliably ensure seismic safety.

The chapter is devoted to a review of the results of a joint 20-year interdisciplinary research led by Professor Sergey Grigorievich Psakhie, the corresponding member of the Russian Academy of Sciences. These studies were aimed at exploring the safe methods of managing deformations (displacements) in the seismically dangerous segments of active faults $[7,8]$. Specialists from various scientific institutions were involved, including the Institute of the Earth's Crust SB RAS (IEC SB RAS), the Institute of Strength Physics and Materials Science SB RAS (ISPMS SB RAS), the Institute of Geosphere Dynamics RAS (IDG RAS), Technische Universität Berlin (TU Berlin), as well as other scientific institutions from Ukraine, Mongolia, and China. The success achieved was largely related to the use of diverse scientific approaches and methods including computer simulation, laboratory physical modeling, and field experiments in rock massifs and regions of the block-structured ice cover of Lake Baikal. Such a variety of techniques and objects of study made it possible to take a fresh look at the nature and mechanisms of destruction processes in the earth's crust and reveal a set of criteria governing the occurrence of seismically dangerous dynamic phenomena in zones of deep faults.

In the chapter, we outline key aspects of this multidisciplinary research.

In particular, we describe the results of a detailed geological, geophysical, and petrological study of the structure and physicochemical transformations of rocks in earthquake foci in the deep horizons of faults. Such information was obtained through examining the deeply denudated blocks of rocks in the fault zones, which were exhumed to the earth's surface from depths of 10-20 km. Using new methods of 
analysis, a number of representative deep segments of fault zones (deep paleoseismic dislocations) were studied in detail. The main attention was paid to segments, which were the centers of earthquakes in past epochs of geological evolution.

Significant efforts of the collaboration participants were directed at conducting field experiments to study the complex mechanisms of the formation of seismic radiation sources. The advantages of such experiments over laboratory tests on small samples of artificial and natural materials are the large size of the studied objects (segments of fault zones tens or hundreds of meters long), the interrelation between the studied objects and the surrounding rocks, the possibility of using broadband seismic stations and strain gages, as well as the possibility of modeling various impacts using high-power jacks, pile drivers and weak explosions. Emphasis was placed on revealing the effect of the impacts on the features of changing the displacement mode in the studied fault segments from slow creep to accelerated creep and coseismic slip. These features largely determine the generation of seismic oscillations of a wide amplitude-frequency range.

Based on a comprehensive analysis of the results of geological and geophysical studies of deep paleoseismic dislocations, field experiments, and numerical modeling, we formulated the concept of the response of faults to external actions and the approach to controlling and managing deformations in fault segments using man-made vibro-pulse and hydraulic wave impacts. Due to the limited effectiveness of numerical modeling and low-scale field experiments in the near-surface part of the earth's crust, the authors cooperated with deep drilling specialists, which have high competence in the exploration and exploitation of hydrocarbon deposits in the Late Proterozoic crystalline formations of the Siberian Craton [9, 10]. The combination of dynamic mechanical impacts with the injection of solutions into fault segments through deep multidirectional wells significantly expands the possibilities of the developed approach to managing displacements in seismically dangerous fault segments. Here we also discuss the prospects of hydraulic wave impacts on deep seismically active segments by means of drilling horizontal, inclined, and vertical wells up to 5-7 km deep, hydraulic fracturing of rock massifs, and injection of solutions of various compositions.

Finally, we consider the difficulties of implementing a complex impact on the deep fault segments and provide a brief overview of current and planned studies by different scientific groups.

\section{Methodological Basis}

Of the many earthquake source focal models known in the world, the "stick-slip" model is considered to be the optimal and most general model [11,12]. It is based on the fundamental tribological laws of sliding friction in seismic-generating fault zones, which have a textured roughness, specific mineralization, and fluid saturation. This model uses the main achievements of tribology and, in particular, takes into account the influence of such frictional parameters as the ratio of shear and normal 
resistance forces (characterized by stiffness ratio), roughness, the variation of sliding velocity, the presence of lubricant, wear of the sliding surfaces, vibrations, etc. [13]. Detailed geological and experimental study of fracture processes in rock massifs has shown that the fundamental tribological patterns of creep or stick-slip sliding can be successfully used to determine the causes and mechanisms of strong earthquakes in fault segments $[14,15]$.

To clarify the conditions of earthquake preparation, we studied the zones of seismic dislocations that formed not only with modern earthquakes but also with paleo-earthquakes. Traces of such ancient earthquakes are captured in the seismic focal horizons of the denudated crust. During the long geodynamic evolution of the lithospheric shell of the Earth, these horizons were on the Earth's surface in the orogeny regions after kilometers-long denudation. They are currently available for visual geological exploration. To obtain a more in-depth understanding of the real structure of the deep segments of the sources of strong earthquakes, these studies were conducted in the Baikal rift zone and the collision zones in Mongolia. The results of these studies are discussed below.

From the viewpoint of practical geodynamic applications of the methods of physical mesomechanics, it is advisable to consider the lithospheric shell of our planet as the upper hierarchically organized geosphere in which the seismotectonic destruction process occurs at various scales according to well-known geomechanical laws. In particular, various tribochemical and geomechanical processes manifest themselves at various hierarchical scales of the earth's crust. According to the well-known kinetic concept of the strength of solids by S. N. Zhurkov and his followers [16, 17], multiscale fracture-related processes manifest themselves in stage-by-stage accumulation of small discontinuities and their coalescence into longer ones due to the fracture of the separating "jumpers" (structural barriers). This can be observed in geological destructive processes. Hierarchical transitions within the self-organized process of destruction of the earth's crust reach the highest level in the form of the formation of intraplate and interplate seismic faults with a length of hundreds to thousands of kilometers.

The basic geomechanical model of a seismically active fault is based on the idea that a focus of a very strong earthquake with $M=7.0-9.0$ is formed as a result of successive long and multi-stage coalescence of faults ranging from the first tens of kilometers to longer ones $(70-120 \mathrm{~km})$. This is clearly illustrated by many recent strong earthquakes, such as the Gobi-Altai earthquake of 1957 ( $M=7.9$ ). To find out the conditions for the formation of different-scale foci of earthquakes (including foci of super-earthquakes) and mechanisms of fracture of these interface zones, the authors use a multiscale approach. It is based on the data of many years of field experiments, geological and structural studies, and numerical modeling using the method of movable cellular automata. On each scale, specific tribochemical and geomechanical factors that determine the features of contact interactions, including the frictional regimes, can be distinguished. The friction features, in turn, affect the amplitude-frequency and energy parameters of the generation of seismic vibrations 
[18]. Further development of this concept is associated with an analysis of the geomechanical consequences of fracture of structural barriers and contact interactions of different scale asperities on the glide planes of the fault limbs.

Pore fluids play an important and, in some cases, determining role in petrochemical processes in zones of highly stressed and seismically dangerous faults. Interstitial fluid largely determines the slip modes, and therefore, the modes and features of the generation of seismic vibrations $[19,20]$. Traditionally, the term "fluids" include liquids and gases that fill void spaces arising from deformation in rock masses. Fluids are also magmatic melts, which themselves are sources of hydrothermal fluids ascending to the earth's surface through conducting faults [21]. The migration of fluid solutions affects the shear resistance of the faults through the lubrication and hydraulic effects on the walls of the fractured rock. Therefore, the pore fluid should be taken into account among key factors that control the nucleation and dynamics of coseismic displacements in discontinuities of different hierarchical levels.

\section{Geological Study of Exhumed Seismic Dislocations of Paleo-Earthquakes in the Southeastern Boundary of the Siberian Craton}

To determine the deep-seated conditions for the modern earthquakes, a collaboration of scientists from IEC SB RAS and IDG RAS carried out a geological and geophysical study of the exhumed deep segments of the Primorsky section of the marginal zone on the southeastern marginal seam of the ancient Siberian craton. Due to natural exhumation from the middle depths of the earth's crust, deep fault segments are now available for study. Here, the traces of different age foci of paleo-earthquakes (ancient coseismic slips) formed at elevated temperatures and pressures are preserved. We note that similar P-T conditions currently exist at depths of 10-25 km, where the seismic focal horizon is located and most of the modern earthquake foci of various energy scales occur (including the strongest events with $M=7.0-7.9$ ). Many of them are confined to the zone of the Primorsky riftogenic fault with a length of about $200 \mathrm{~km}$. This fault is located on the northwestern coast of the Baikal rift depression (Fig. 1) and was formed for $65 \mathrm{Ma}$. It is important to note that the deeply denudated (exhumed) Pribaikalsky segment of the fault allows the visual study of the structure and P-T conditions for the formation of ancient earthquakes of different ages (including those with an age of the order of 700-450 Ma) at activation depths of 12-18 km [22].

Ancient sliding mirrors, formed during the dynamic interaction of irregularities, were sampled in this fault segment (Fig. 2). The samples were subjected to petrological studies using the polished sections. Tectonites (rocks transformed by the friction of rocks) taken in the zone of later earthquakes have indications of gneissing, cataclase, and milonitization in the Early Paleozoic period. To elucidate the natural conditions of tribochemical processes in the deep foci of paleo-earthquakes and 


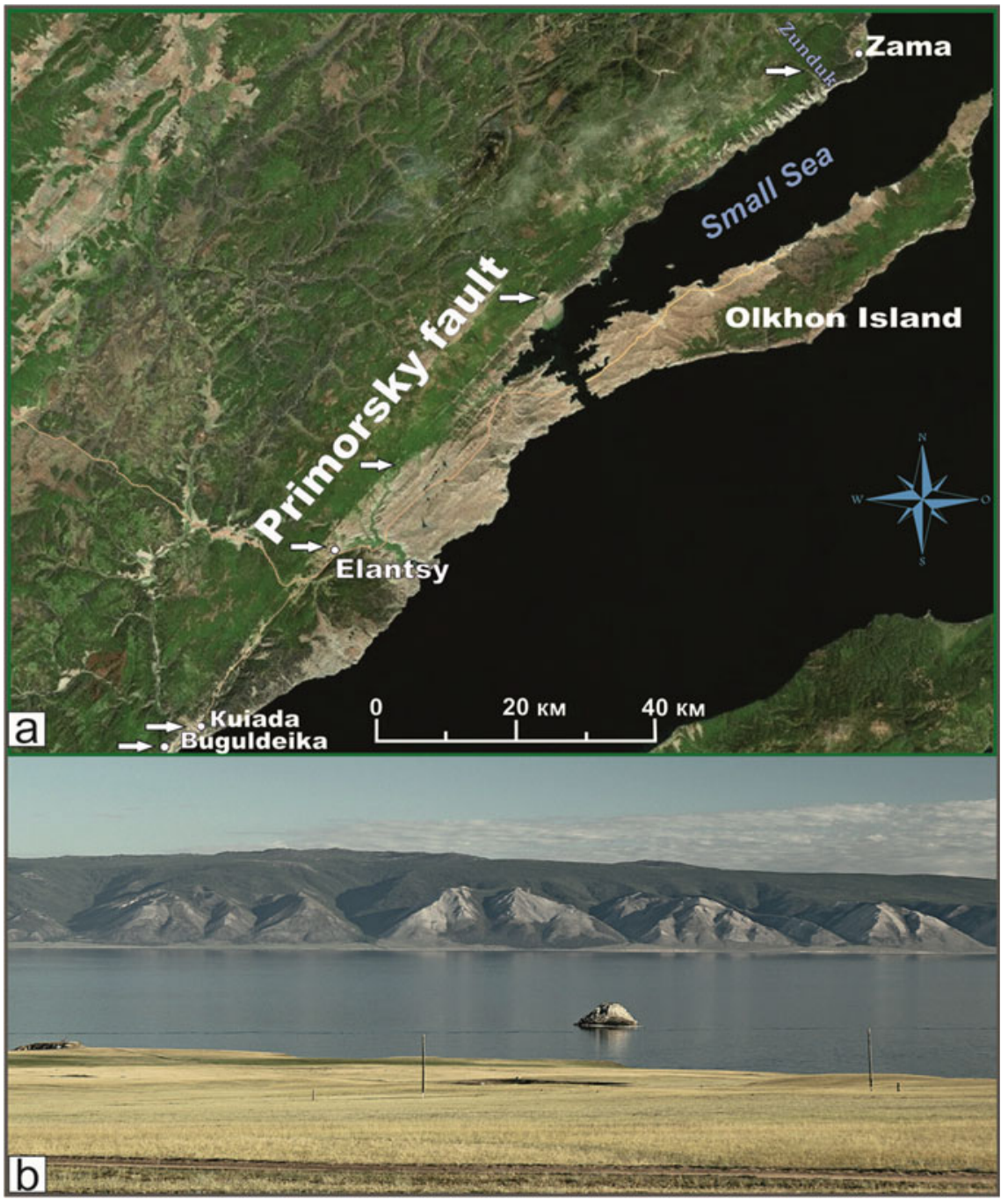

Fig. 1 Morphological expression of the Primorsky riftogenic zone: view from space (a) and one of the sections on the shore of the Small Sea (b). The arrows in (a) indicate the test sites where a comprehensive study of ancient coseismic displacements was carried out. These displacements occurred hundreds of millions of years ago in the centers of paleo-earthquakes at depths of about $15-20 \mathrm{~km}$, at high temperatures and pressures

the structure of contact spots with traces of coseismic slip, we carried out a petrological study of changes in the material composition of the mineral coating on slip planes. Coseismic slip and the structure of the surface layers were analyzed by sliding mirrors containing indications of high-rate displacements, including pseudotachylyte (products of frictional heating in faults under stress metamorphism at elevated 


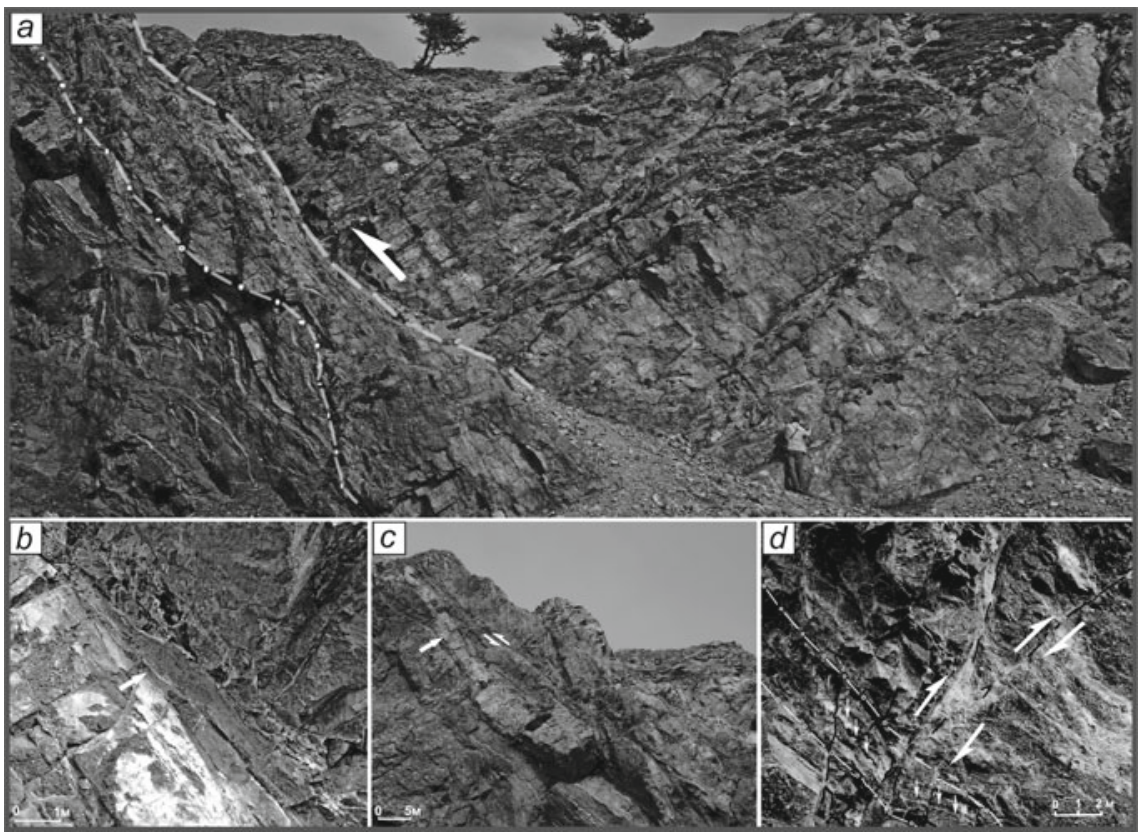

Fig. 2 Coseismic fractures of different ages containing multiscale asperities in the centers of paleoearthquakes at seismic focal depths from $5 \mathrm{~km}$ to $12-18 \mathrm{~km}$ : a the oldest coseismic slip zone at a depth of about $18 \mathrm{~km}$; b low-scale roughness in a small coseismic rupture; $\mathbf{c}$ longer coseismic rupture and "macroasperity" shown by the arrow; $\mathbf{d}$ intersecting coseismic ruptures that occurred at different times and different depths and PT conditions, as shown by minerals deposited from fluids. The dash-dot line in (a) shows the oldest coseismic slip zone at a depth of about $18 \mathrm{~km}$. The dashed line and the arrow to the right (slip direction) denote the younger zone of coseismic slip. Slip mirrors and newly formed mineralization with traces of thermal heating during friction were taken from this zone

temperatures, pressures, and the participation of fluids). Recently, G.A. Sobolev and his colleagues demonstrated the possibility of efficient application of modern physical methods for determining strains and stresses in fine ground nanocrystals of various minerals, including quartz, albite, chlorite, epidote, and other varieties found on sliding mirrors from the exhumed segment of the Vilyui deep fault [23, 24]. Consequently, tectonic glide mirrors identified at fault exhumation sites, as well as pseudotachylyte, can be used to recognize and analyze coseismic planes. This makes it possible to obtain important information about the kinematics and tribophysical processes in the deep fault segments at the moments of the generation of seismic events by the examples of past tectonic eras.

The analysis of the slip mirrors showed the finest brittle attrition of minerals. This is typical for high-velocity sliding. The important role of fluids in eliminating (healing) the consequences of fracture is illustrated through the presence of finegrained aggregates of quartz grains and feldspars with a subordinate amount of sericite, chlorite, and iron ore minerals. It is important to note that such mineral 


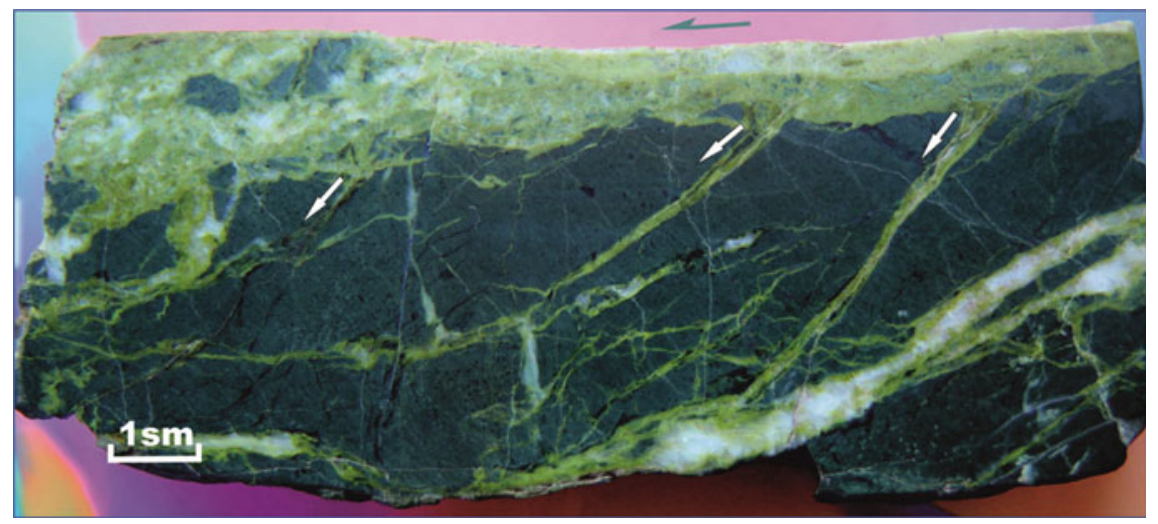

Fig. 3 The cross-section of a sample of an ancient sliding mirror taken from the zone of the exhumed segment of the Dolinozersky Fault (still highly seismic hazardous) in southern Mongolia. It captures the consequences of two acts of coseismic slip (the arrow at the upper edge) with the "healing" by the epidote and subsequent quartz mineralization

neoformations have a reduced shear resistance and can play the role of a mineral lubricant that facilitates subsequent sliding acts and prevents reverse closure of crack walls. Sliding of rough walls of the fault is accompanied by crack opening (dilatancy), and mineralized fluids are sucked into the vacuum gap. This ensures filling the cavities with new minerals, including ore. This is the hydrothermal mechanism of mineral "healing" of fault segments in the upper part of the earth's crust at relatively low pressures and temperatures [25].

The collected information on the dating of identified coseismic planes and the P-T-f conditions for the formation of slip mirrors and pseudotachylyte was used to make a qualitative and quantitative estimation of the exhumation of the Primorsky section of the margin, as well as of the structure of the seismic focal horizon. In particular, the oldest absolute dating established by the ${ }^{40} \mathrm{Ar} /{ }^{39} \mathrm{Ar}$ method is $673 \pm$ 4.8 Ma. This corresponds to one of the stages of the Neoproterozoic era, i.e., the time of break-up of the Rodinia supercontinent and the separation of the Siberian craton along the margin. $415.4 \pm 4.1$ Ma refers to a later stage in the evolution of the margin during the collision of the Olkhon terrane with the Siberian craton [22]. The obtained dating made it possible to roughly estimate the occurrence depths of the identified strong paleo-earthquakes. They amounted to about $18 \mathrm{~km}$ in the earlier (Neoproterozoic) period, and about $12 \mathrm{~km}$ in the later (Middle Paleozoic) stage [22]. Similar results were obtained in the neighboring section of the Primorsky fault $(5 \mathrm{~km}$ to the northeast). In the coseismic slip plane, the temperature of frictional heating during the occurrence of pseudotachylyte reached approximately $900{ }^{\circ} \mathrm{C}$, and the pressure reached 700-800 MPa. After dynamic slip, the pressure rapidly decreased to a "natural" (lithostatic) value, which was estimated as $\leq 150-200 \mathrm{MPa}$ in the considered case. This corresponds to depths of the order of 5-7 km [26]. 
Figure 3 shows a photo of a very ancient sliding mirror taken from the exhumed zone of the Dolinozersky Fault in southern Mongolia. A devastating Gobi-Altai earthquake $(M=7.9)$ occurred here in December 1957.

The polished section shows the internal structure of the coseismic rupture zone with the shearing of asperities on the slip plane and the transfer of fragments of basaltic anorthosite from an ancient volcano. Large and small fragments of the parent rock move within the mass of newly formed chlorite and calcite minerals deposited from the flowing fluid. These minerals healed the fracture cavity. Mineral "healing" products also fill wing cracks that formed under the condition of large friction in combination with the fracture of asperities. Wear debris carries over when sliding in the direction of the white arrows. This is the widespread mechanism of the formation of sources of strong earthquakes accompanied by the occurrence of wing cracks.

Therefore, the geological study of deep segments of fault zones opens up a unique opportunity to reconstruct the conditions for the nucleation of coseismic slips in the areas of the most severe contact interaction of different scale asperities in fault zones with the participation of fluids. The mineralization of the fluid determines the mineral composition of crack fillers. Mineral composition in many respects affects the frictional sliding of the fault walls during subsequent activations. Although the processes of stress-metamorphic transformation of rocks in the considered fault zones at seismic focal depths occurred in past eras of seismotectonic activation, it is clear that the same mechanisms act in modern earthquake foci. Therefore, the database of ancient earthquakes is fundamentally important for creating adequate models of modern earthquake sources [14].

\section{Features of the Response of Tectonic Fault Segments to Man-Caused Impacts}

Below we describe the most important results of field experiments carried out in different years on the segments of the Angarsky and Primorsky faults in the Baikal rift zone.

The first one was carried out in 2004-2006 on the segment of the Angarsky fault zone near the Listvyanka village (southwestern coast of Lake Baikal), Irkutsk Region. The Angarsky fault has a northwestern strike and is characterized by faults of the reverse-strike-slip type. The studies were conducted with the participation of scientific groups of several institutes of the Russian Academy of Sciences, as well as the Technische Universität Berlin. At this test site, the effect of high strain sensitivity of the principal slip zone to natural and man-made impacts was revealed [27]. The most important result of the research is related to the demonstration of the ability to manage the shear displacement mode in the fault zone. In order to carry out manmade impacts on a selected fault segment $100 \mathrm{~m}$ long, several wells were drilled to a depth of $30 \mathrm{~m}$ for 14 days, and water solutions were injected into the fault zone (Fig. 4a). Then local dynamic impacts with weak explosions at a depth of about $15 \mathrm{~m}$ 


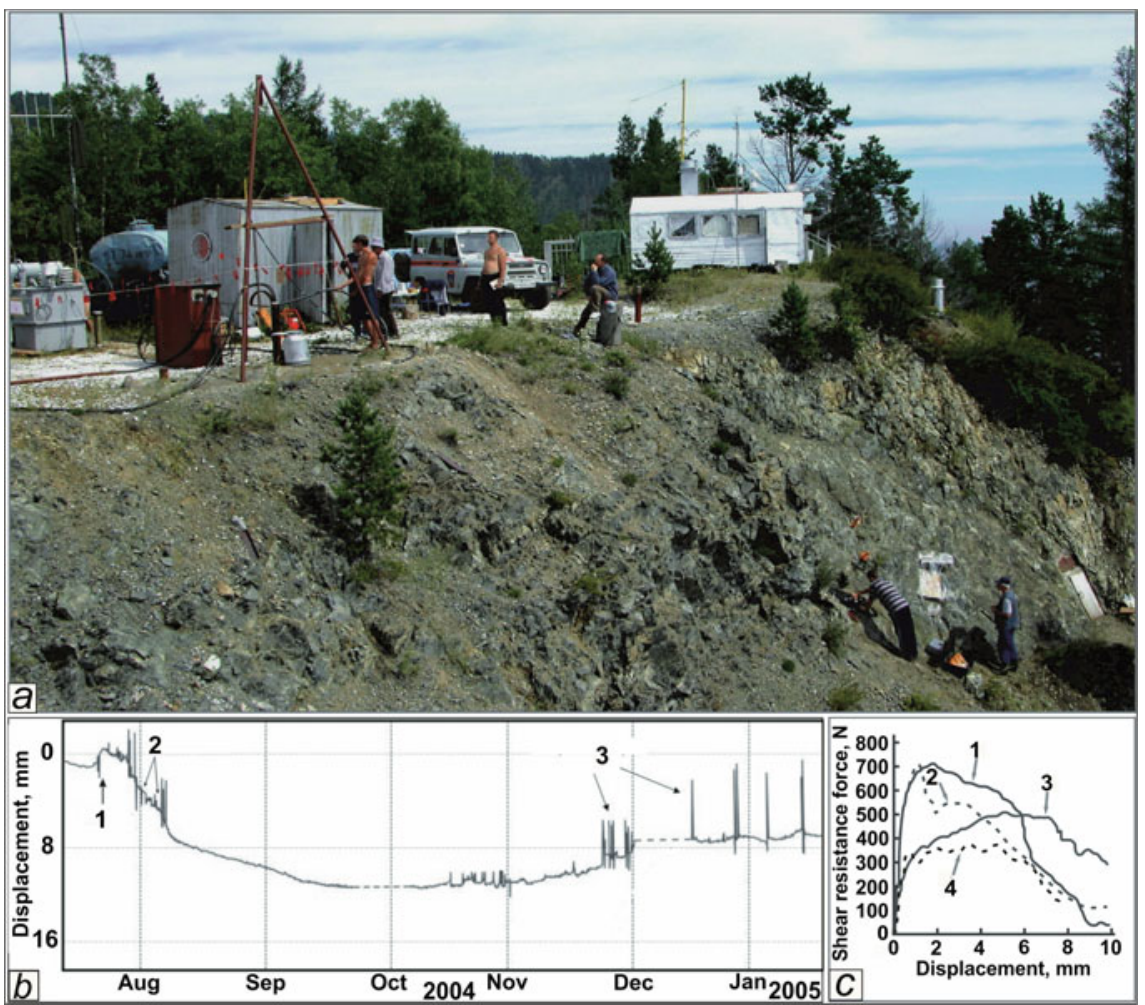

Fig. 4 General view of the test site in the Angarsky fault zone section (a), a graph of shear displacements in the fault zone at different stages of the experiment (b) and results of numerical modeling [7] showing the dependence of the shear resistance on the relative tangential displacement at a constant displacement velocity and various additional actions. Figure (a) shows a part of the test site with three wells for water injection and explosive actions, a platform for a falling pile and locations for strain gages and seismic sensors. The numbers in Figure (b) are as follows: stress tests with a falling pile before the experiment (1); well drilling, water injection, and explosions in the well (2); displacement "jumps" at the stage of return deformation (3). The numbers in Figure (c) are: "dry" fault zone, no additional impacts (1); "dry" fault zone, additional vibration (2); watered fault zone, no additional impacts (3); watered fault zone, additional vibration (4)

in watered wells were carried out at the next stage. To study the effect of the impacts on the stress state of the fault segment, we performed mechanical stress tests on the surface with a falling pile weighing $100 \mathrm{~kg}$. Such tests were performed before and during the whole course of the experiment.

The fault responded in the form of initiated tangential displacements in the principal slip zone. This was recorded by strain and seismic sensors. The vibrations during drilling and subsequent watering of the fault zone, accompanied by weak cumulative explosions in watered wells, have led to a qualitative change in the displacement mode. In particular, the creep velocity increased by several orders of magnitude: from "natural" values of $0.65-3.3 \mu \mathrm{m} /$ day $(0.24 \mathrm{~mm} /$ year $\div 1.2 \mathrm{~mm} /$ year $)$ to $0.5 \mathrm{~mm} / \mathrm{day}$. 
Although the creep acceleration was of a short-term nature (less than a month), the total amplitude of the initiated tangential displacements in the principal slip zone reached 8-10 mm (Fig. 4b). This corresponds to 10 years of accumulation of displacements in the natural mode. Note that in the months after the experiment, a partial recovery (reverse displacement) occurred in the slip plane, and the residual displacement amplitude decreased to 5-6 mm. This is the result of the elastic "return" of the surrounding rock mass. It is noteworthy that the return motion was accompanied by seismic pulses with amplitudes comparable with seismic amplitudes during initiated (accelerated) creep. A similar elastic-plastic partial return with significant "residual" displacements is also observed in seismic dislocations after strong earthquakes. This indicates the generality of the described effect for the zones of tectonic faults.

Field experiments and numerical simulations using the method of movable cellular automata [7] showed that the injection of aqueous solutions into the fault zone in combination with vibroimpulse impact trigger local relaxation of "excess" shear stresses in the fault segment (Fig. 4c). Stress relaxation is manifested particularly in the transition from natural to accelerated creep, followed by its gradual deceleration to natural values determined by regional tectonic motion. Displacement monitoring on the studied segment of the Angarsky fault over 14 years shows slow creep and extremely weak microseismicity. Moreover, the magnitude of deformation and seismic response of the fault segment to the standard dynamic test impacts of the falling pile is one order of magnitude lower than before the experiment. This confirms a considerable decrease in the level of shear stresses. Thus, the field experiment confirmed the statement about the possibility of a controlled change in the slip mode in the segments of fault zones to safely reduce the level of shear stresses and seismic activity $[7,28]$. The developed method of shear stress relaxation in fault segments is protected by a patent of the Russian Federation [29].

From 2015 to 2018 joint research was conducted by the IEC RAS and IDG RAS research teams in the coastal segment of the Primorsky Fault zone on the Baikal coast (near Olkhon Island). The studies included geophysical observation and field experiments. Figure 5 shows a general view of the testing ground. The purpose of the experiments was to study the influence of quasistatic (carried out by jacks) and dynamic (explosive) effects on the displacement mode during contact interaction with a single artificial asperity. A hydraulic flat jack was installed in a large crack in the central part of the fault zone. The crack walls were pulled apart with a force of 43 tons. A $5 \mathrm{~cm}$ thick granite gneiss ore was inserted into the cavity to study the fracture of the rock under conditions of high local compressive stress and additional (man-made) impacts. After the jack was removed, the ore was compressed by the crack walls with the force of the crack extension ( 43 tons).

The processes in the studied segment of the fault zone after the insertion of a single macroasperity were recorded by strain gages and seismometers. After several days of monitoring the natural deformations and the seismic background, a series of weak explosions were performed (the mass of one powder charge was $0.1 \mathrm{~kg}$ ). The explosion chamber was located in the large plate within the fault segment at a distance of $3 \mathrm{~m}$ from the seismic sensors. The recorded amplitude of seismic 


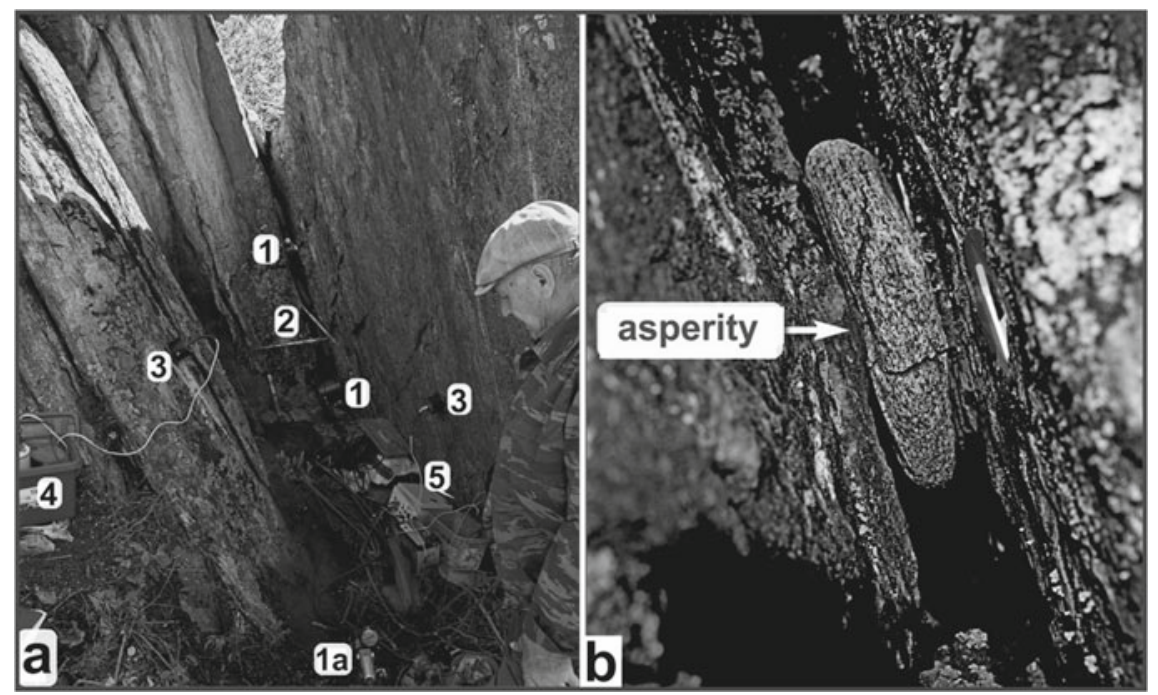

Fig. 5 Studied segment of the Primorsky fault zone with measuring equipment (a) and artificial asperity (granite gneiss ore) with cracks resulting from experiments (b). The numbers in Figure (a) are as follows: jacks (1); pump (1a); displacement sensors (2); seismic sensors (3). The inclined arrow in (b) shows the direction of the natural normal faulting displacement

acceleration during the explosion was $219 \mathrm{~cm} / \mathrm{s}^{2}$, and the frequency was about 70 $75 \mathrm{~Hz}$. Figure 6 shows a seismic recording for $330 \mathrm{~min}$ after the explosion. It reflects the result of contact interaction during the explosion, in particular, the initiated slip

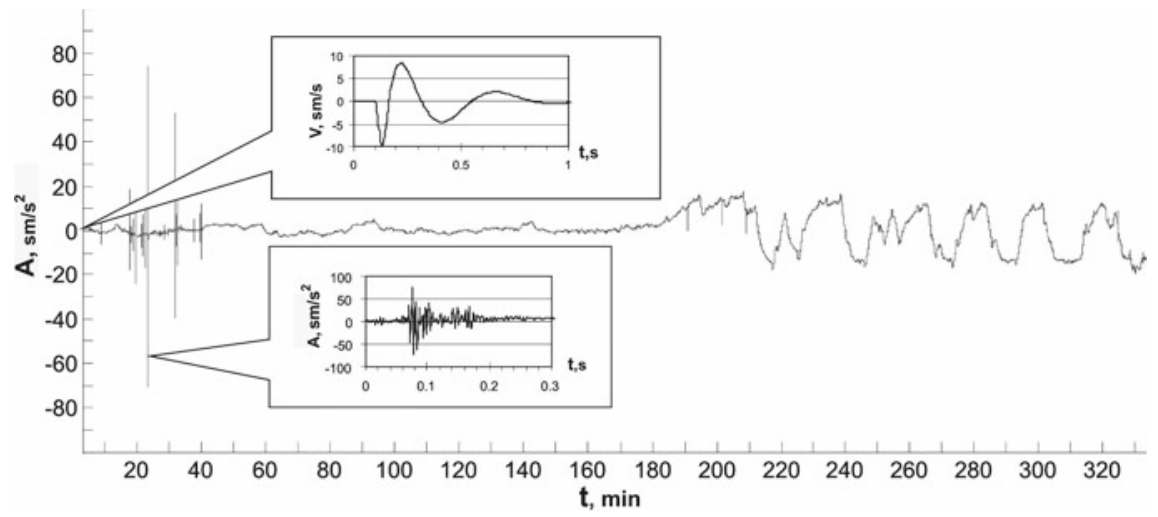

Fig. 6 Response to explosive action in one of the cracks in the Primorsky fault zone. The main figure shows the general view of the seismic record within $330 \mathrm{~min}$ after the explosion. The upper inset shows the oscillation velocity of the rock mass for $1 \mathrm{~s}$ and its upper value of $0.7 \mathrm{~mm} / \mathrm{s}$. The bottom inset shows the record of the first induced seismic response (the largest seismic pulse) that occurred $22 \mathrm{~min}$ after the explosion (amplitude $70 \mathrm{~cm} / \mathrm{s}^{2}$, frequency $160-175 \mathrm{~Hz}$ ) 
in the contact pair "crack wall-ore". Within 40 min after the explosion (with some delay) a series of strong seismic pulses (response to the explosion) were formed. Pulse amplitudes reached several tens of percent of the acceleration amplitudes during the explosion.

The measurements and visual observation showed that stress relaxation and redistribution in the surrounding massif after the explosion promote reaching the critical stresses at the contacts of the artificial asperity with the crack walls and cracking of the ore after some time (tens of minutes) after the explosion. Cracks propagated in the ore in the dynamic regime and were accompanied by the generation of a series of large seismic pulses. In Fig. 6, these pulses are shown on the left side (time interval of 15-40 min after the moment of explosion).

An analysis of the record of displacements in the main crack showed moderate compressive deformations of the crack with characteristic amplitudes of 25-35 $\mu \mathrm{m}$ in combination with reverse faulting during the period of the subsequent "calm". The largest seismic impulse was associated with the fracture of the artificial asperity and characterized by the following parameters: amplitude $70 \mathrm{~cm} / \mathrm{s}^{2}$, frequency 160 $175 \mathrm{~Hz}$. The next phase of the response began $190 \mathrm{~min}$ after the explosion and lasted about $140 \mathrm{~min}$. It is characterized by low-frequency "pulses" with an average period of about $18 \mathrm{~min}$ and acceleration amplitudes of $15-20 \mathrm{~cm} / \mathrm{s}^{2}$. The generation of such extremely slow seismic pulses is a deformation response of the rock massif to a dynamic disturbance of a local stress state. The response manifests itself in the form of a return slip and can be described by viscoelastic models.

This example demonstrates the generation of high-velocity elastic and subsequent slowed-down oscillations of the rock massif caused by the intermittent slip mode at the contact with the large-scale asperity. It is noteworthy that the unloading of the surrounding rock mass manifested itself in the form of intermittent slip described by the stick-slip model, with the generation of slow deformation waves. In subsequent similar tests, the contact area of the ore and the crack walls was wetted. This led to the initiation of small cracks in the artificial asperity at the contact point accompanied by numerous packets of audible seismic-acoustic pulses. Over the subsequent months of application of natural static pressure by the rock mass, the ore gradually split into several large fragments.

The described experiment showed that an explosive (high-velocity) impact causes a strong viscoelastic-plastic return accompanied by high-amplitude seismic pulses and subsequent slow motions. These slow oscillations can presumably be regarded as being analog to slow waves associated with intermittent sliding of contacting surfaces in interplate faults [30,31]. In this case, the observed propagation phenomena of slow waves are apparently associated with the phenomena of self-organization of ensembles of cracks in the rock mass (cracks are highly sensitive to the rate and amplitudes of external dynamic impacts). Note that slow motions were clearly recorded in other (larger-scale) experiments including technological explosions with multi-ton explosive charges in the quarry of the Udachnaya diamond pipe.

Based on the results of the above field experiments, as well as many other tests, we can draw an important conclusion. Safe stress relaxation in highly stressed (seismically hazardous) segments of tectonic fault zones can be achieved using local 
impacts with low impact velocities and energies [32]. An additional and extremely effective relaxation stimulation is the saturation of contact slip surfaces with aqueous solutions, especially when the physicochemical properties of the liquid determine the important role of the Rehbinder effect [33, 34].

\section{Prospects for the Implementation of Controlled Impacts on Fault Segments Through Deep Wells}

The examples discussed above consider methods of managing impacts on small near-surface areas of seismically active faults. The question remains whether these experiments can be extended to the scales of the long fault segments and deep regions characterized by high pressures and temperatures, and complex fluid circulation. To answer this question, we consider the possibility of implementing control actions on segments of deep sections of fault zones through wells up to 3-5 km deep. Here we can take the experience of drilling such wells within the ancient Siberian platform for injecting solutions and hydraulic fracturing. Such work is carried out, particularly, at hydrocarbon deposits in the Republic of Yakutia (Russia), where hydrocarbon reservoirs are at relatively shallow depths of about $2 \mathrm{~km}$.

Deep drilling and hydraulic fracturing allow to open the natural fluid fracture-pore reservoirs containing oil, gas, and saltwater. It should be noted that the magnitude of the pressure in such reservoirs is often close to rock pressure. The application of this technology allows the use of fluid injection at a given pressure through a network of inclined wells as a hydraulic action on the walls of the principal slip plane, ensuring their opening or closing [35]. The hydraulic effect of the injected fluid can be compared to a first approximation with the action of a powerful hydraulic jack (the role of the jack is played by the fluid pumped under pressure). The effect of fluid saturation in combination with hydraulic fracturing reduces friction and changes the slip mode of the fault limbs at the injection sites.

Man-made pressure effects transmitted through the reservoir fluid system allow the fractured reservoir (within the hydraulic influence region) to be transferred to another stress state. These effects include the influence on the value of shear resistance in the segments of the drilled sections of the fault zones. When the seam pressure is reduced to a certain level, the permeability of the rock decreases, cracks close, and, therefore, friction and shear resistance increase. To re-open the cracks, it is necessary to re-increase the pressure of the fluid system to an appropriate level. This makes it possible to control the stress-strain state of fault segments and the mode of their seismic activity [36]. It is also important to take into account the natural ratio of the angles of inclination of fault zones with the vertical direction of gravity.

It is known that vertical cracks in the strike-slip fault zones have greater openness than inclined ones since the rock pressure on the walls of vertical cracks is much less than on the walls of inclined (and especially mildly sloping) cracks. Accordingly, the shear resistance of vertical cracks is also significantly less. In particular, during 
the drilling of reservoirs within the zones of subvertical faults, seam pressure can sharply drop to the value of pore pressure in the surrounding rock mass [37]. Another situation occurs with the subhorizontal inclination of the principal slip zone of a thrust fault. Here, the natural fluid system can be at extremely high pressures due to push-up conditions. In such cases, the use of standard drilling technologies can lead to strong dynamic responses of fault zones, especially in the absence of pore fluids. Injection of drilling fluid into the zones of subhorizontal fractures can lead to a sharp decrease in shear resistance and activation of coseismic displacements.

Injection of solutions into the fault at a controlled rate allows managing pressure drop and the frictional resistance of the fault zone, as was shown by experimental studies. Such technological impacts on highly stressed fault segments can be supplemented by the use of proppants to change the slip mode. Natural proppant-fixed cracks are colmataged, which prevents them from closing. Another technique is the use of additives in drilling fluids, for example, granules of copolymers (alpine drill beads). Such additives contribute to a decrease in frictional resistance in the contact spots of asperities in the fault zone and to a decrease in the critical density of accumulated elastic strain energy at which seismic vibrations are generated. The latter leads to a decrease in the amplitude of seismic oscillations.

Local hydrodynamic and tectonic conditions must be taken into account during the drilling process. For example, natural filtering fracture simplifies fluid injection and pellet delivery into the fault through drilled fan lateral branches in horizontal fishbones. At a subhorizontal slope of the principal slip zone of the thrust fault, the natural fluid system can be at extremely high pressures due to push-up conditions. This contributes to the creation of frictional instabilities in the fault zone. Upon identifying such features by geological and geophysical data, special measures to reduce seismic risk have to be developed.

Deep drilling of injection wells to depths of 5-7 km in the fault zones shows that the injection pressure and fluid saturation are able to propagate to much deeper horizons due to hydraulic connection with existing natural fluid systems. This indicates a real possibility of man-made impacts on seismically hazardous deep fault segments through deep wells since such impacts can reach the level of the seismic focal layer in the continental crust.

The example shown below is one of the options for drilling a well-studied segment of the Tunka fault in the Baikal rift zone near the Arshan settlement (Irkutsk Region, Russia). Some volcanic apparatuses and coseismic fractures of 4 destructive earthquakes $\left(\mathrm{M}_{\mathrm{w}} \sim 7.5\right.$, the average recurrence period is $3.9 \pm 0.6$ thousand years) were found in the vicinity of this segment. The latest paleoseismic dislocation in this area is about 1 thousand years old. We also note the recent strong earthquake of August 22,1814 , in the neighboring segment of the Tunka fault zone. The energy of the tremors was about 9 balls. Currently, there is a seismic gap in the Arshan segment of the fault, which is a warning sign of the preparation of the next stage of activation in the coming years or the first decades. Based on these assumptions, the seismic situation in the Arshan segment of the Tunka fault can be assessed as potentially dangerous. 


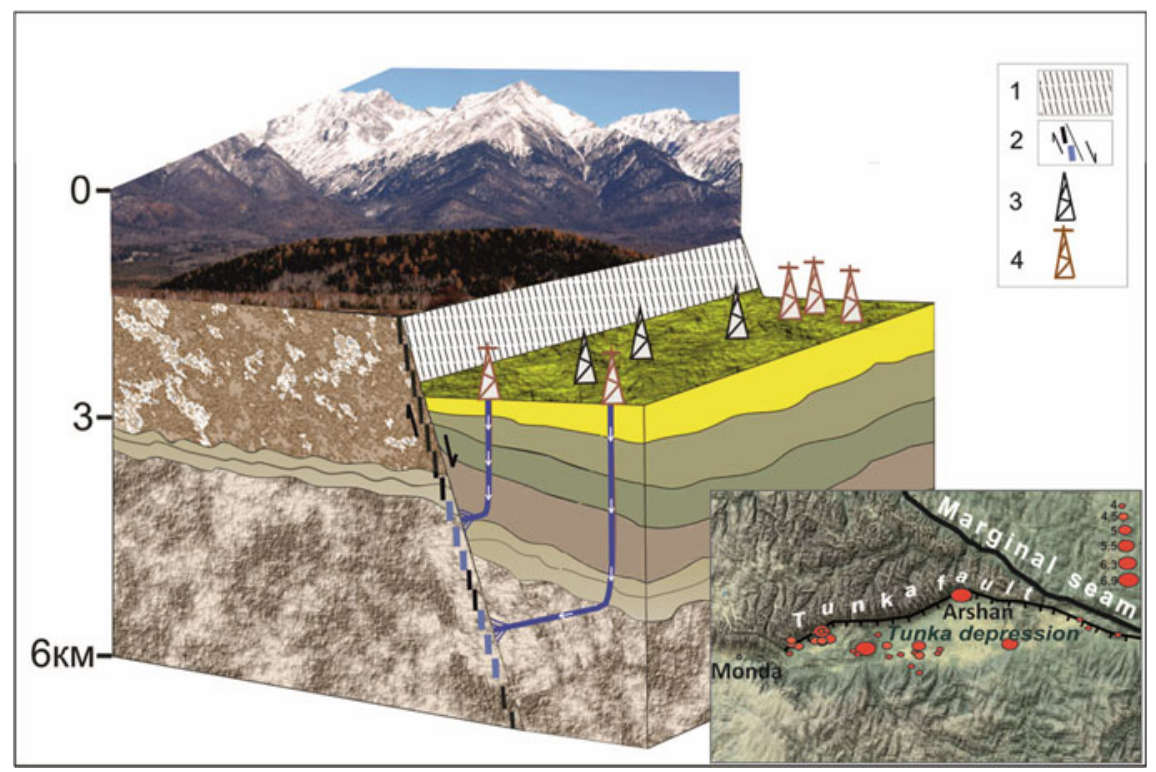

Fig. 7 The scheme of the proposed placement of two groups of inclined injection and monitoring wells for sequential hydrodynamic vibro-pulse impacts on the Arshan segment of the Tunka fault. The inset shows the central part of the Tunka rift basin, the Arshan segment of the Tunka fault zone, and the epicenters of earthquakes $M_{w}=4.0-6.9$ over the past 70 years

Therefore, this segment is an appropriate place to validate the method of preventive relaxation of shear stresses using a hydraulic injection of fluids with controlled pressure into the fracture zone through a network of deep inclined or horizontal multilateral wells $[38,39]$. Below is a simplified block diagram of the planned test site in the Arshan segment of the Tunka rift faulting zone (Fig. 7).

The advantages of using modern technology for driving deep wells into fault zones are determined by the possibility to control the volume and modes of injection of different solutions. Nevertheless, it is necessary to take into account the complex additional factors (geophysical, seismotectonic and geostructural), including the spatial orientation of principal slip zones with respect to the main axes of tectonic stresses, the length and thickness of fault zones, the values of dip angles, triple junctions, etc. It is also important to conduct preliminary test actions to assess the features of the "macroscopic" response of the fault zone.

\section{Discussion}

When discussing the results of the described interdisciplinary studies aimed at developing an approach to the man-made management of displacement modes in fault 
zones, it is important to consider the similar experience of foreign scientific groups. In particular, it is necessary to take into account the known results of studying the consequences of injecting solutions through wells $3-5 \mathrm{~km}$ deep. The watering of fault zones sometimes led to the initiation of many weak earthquakes. Hypocenters of earthquakes extended in depth to distances commensurate with the length of the wells themselves. This indicates fluid saturation of rock masses in much deeper horizons. The authors of the monograph [40] studied indirect seismological evidence of high and rapidly changing permeability of the middle and lower crust from data on the systematic emergence of hypocenters of aftershock sequences of strong earthquakes. Such a notion can be considered as an indication of the presence of a hydraulic connection between fluids of the lower and middle crust with hydrological systems in the surface layers of the earth's crust. Thus, fluid injected through insufficiently deep wells $(3-5 \mathrm{~km})$ can hydraulically act on deeper fluid-saturated layers of the earth's crust down to the depths of preparation of the sources of strong earthquakes. This way is assumed in the framework of the proposed approach.

Laboratory tribological studies indicate that many classical laws of friction are valid for zones of active tectonic faults and determine the regimes of seismic activity in deep fault horizons [13, 41, 42]. This means that the regimes of radiation of seismic vibrations during tectonic creep or coseismic slip should be considered as the results of visco-elastic-plastic contact interactions between randomly rough sliding surfaces. Classical tribological laws also hold upon transitions to higher hierarchical levels of seismotectonic destruction in the lithosphere. This refers, for example, to transient frictional slip regimes from aseismic to accelerated ones, or dynamic failure in the final stage of earthquake preparation. These regimes, in turn, affect the amplitude-frequency and energy parameters of the radiated seismic vibrations. The injection of aqueous solutions into fault zones not only reduces the strength characteristics of rocks and shear resistance in slip planes but also promotes a hydraulic (wedging apart) effect. The latter causes hydraulic fracturing or slow opening of natural cracks and hence reduces the contact area and the friction coefficient. The experience gained during the operation of underground hydrocarbon storage, the extraction of geothermal resources, and the development of gas and oil fields in seismically active regions show that aqueous solutions injected through wells under high pressure can reactivate existing deep fault segments and provoke dangerous earthquakes with $\mathrm{M}_{\mathrm{w}} \geq 4.0-5.2$ [43-46]. Many authors are of the opinion that the unintentional activation of faults caused by fluid injection should be used instead to manage the relaxation of excess stresses in fault zones. To implement this in practice, it is necessary to identify and use tribological mechanisms that control slip modes and generation of seismic vibrations in fault zones [47]. It was shown above that such knowledge helps to exclude the acts of strong seismic activation of fault segments at significant distances from injection wells.

Many representatives of the scientific community believe that even energetically moderate technogenic impacts including hydraulic fracturing by injecting drilling fluids can induce strong earthquakes even in aseismic areas. Examples are geological exploration and exploitation of underground geothermal water resources in Texas 
(USA) and Switzerland [48]. However, experience of deep drilling in the exploration and development of hydrocarbon deposits in aseismic regions (including the Siberian platform), indicates the absence of such dangerous phenomena. Note that even underground nuclear explosions with megaton charges were not able to trigger multiscale transitions to merge small faults into a long seismically active fault and initiate destructive earthquakes with $\mathrm{M}_{\mathrm{w}} \geq 7$ [49]. Nevertheless, we cannot exclude induced low-energy seismicity in the form of a series of moderate earthquakes. The most striking example is the recent Bachat man-provoked seismic event in Kuzbass (Russia) on 18.06.2013 $\left(\mathrm{M}_{\mathrm{w}}=6.1\right)$ with a hypocenter depth of $4 \mathrm{~km} \mathrm{[50].} \mathrm{It} \mathrm{was}$ initiated after long-term mining operations in coal mining at depths of up to $2 \mathrm{~km}$. This extraordinary earthquake is the result of regular powerful explosions, as well as the excavation of large volumes of rock mass over an area of $100 \mathrm{~km}^{2}$.

The magnitude of the most well-known (and rather rare) technologically induced moderately hazardous earthquakes induced by mining operations ranges within 2.86.1. There are some examples of the initiation of strong earthquakes with $\mathrm{M}_{\mathrm{w}}=7$ as a result of the uncontrolled long-term withdrawal of huge volumes of oil and gas from deep-seated deposits. This kind of phenomena took place near the city Gazli or the city Neftegorsk. A huge number of such examples show that the increasing power of anthropogenic impact on the upper layers of the earth's crust leads to the unintentional provocation of dangerous seismodynamic phenomena. This makes it necessary to mobilize the efforts of the scientific community to prevent such kind of phenomena. The proposed approach can be efficiently used to solve this problem.

\section{Conclusion}

Uncontrolled long-term high-energy man-made impacts on highly stressed areas of the earth's crust are increasingly leading to unintended seismic disasters. We showed the possibility to prevent or neutralize such disasters by implementing proactive measures including controlled vibration-pulse actions in combination with controlled injections of solutions through deep wells. Such kind of technology is based on the approach, which integrates advanced geological and geophysical methods in combination with advanced deep drilling technologies and numerical and physical modeling. This will make it possible, in the near future, to provide a more reliable solution to the global problem of ensuring seismic safety. The results considered above provide the basis for conclusions about the feasibility of projects aimed at effectively reducing seismic risk [51].

Professor S. G. Psakhie was among the drivers of the development of the approach to managing the displacement mode and seismic activity of highly stressed fault zones. At various seminars, we discussed the prospects of the implementation of large-scale field tests using vibro-pulse and hydraulic methods of influencing segments of seismically dangerous fault zones through drilled deep wells. The most challenging problems are appropriate funding, government approvals, and the preparation of test sites in areas, which are at a safe distance from settlements. Such test 
sites are available, for example, in the poorly populated territory of the Mongolian People's Republic, where seismic and geological studies have revealed a system of deep seismic hazardous faults. To create a technology aimed at solving the described multidisciplinary problem, combined efforts of the world community and the support of governments are required. The next immediate task for the implementation of such an important project is to organize a series of large-scale field tests in the segments of seismically dangerous faults using advanced deep drilling technologies.

Acknowledgements The authors are grateful to the great number of participants in the many years of research. The authors express especially grateful memory and deep gratitude to Professor S. G. Psakhie as the organizer, teacher, author, and mastermind of the studies aimed at solving the global problem of ensuring the seismic safety of the human community. The work was performed according to the Government research assignments for IEC SB RAS (V.V.R.), and for ISPMS SB RAS (E.V.S.).

\section{References}

1. Ogata Y (2017) Statistics of earthquake activity: models and methods for earthquake predictability studies. Annu Rev Earth Planet Sci 45:497-527. https://doi.org/10.1146/annurevearth-063016-015918

2. Booth E (2018) Dealing with earthquakes: the practice of seismic engineering 'as if people mattered.' Bull Earthq Eng 6:1661-1724. https://doi.org/10.1007/s10518-017-0302-8

3. Panza FG, Kossobokov VG, Peresan A, Nekrasova K (2014) Earthquake hazard, risk and disasters. Academic Press, Cambridge, UK, pp 309-357 (Why are the Standard Probabilistic Methods of Estimating Seismic Hazard and Risks Too Often Wrong). https://doi.org/10.1016/ B978-0-12-394848-9.00012-2

4. Chen X, Nakata N, Pennington C, Haffener J, Chang JC, He X, Zhan Z, Ni S, Walter JI (2017) The Pawnee earthquake as a result of the interplay among injection, faults and foreshocks. Sci Rep 7:4945. https://doi.org/10.1038/s41598-017-04992-z

5. Miller S (2013) The role of fluids in tectonic and earthquake processes. Adv Geophys 54:1-46. https://doi.org/10.1016/B978-0-12-380940-7.00001-9

6. Ruzhich VV, Psakhie SG, Shilko EV, Vakhromeev AG, Levina EA (2019) On the possibility of development of the technology for managing seismotectonic displacements in fault zones. AIP Conf Proc 2051:020261. https://doi.org/10.1063/1.5083504

7. Psakhie SG, Ruzhich VV, Shilko EV, Popov VL, Astafurov SV (2007) A new way to manage displacements in zones of active faults. Tribol Int 40:995-1003. https://doi.org/10.1016/j.tri boint.2006.02.021

8. Ruzhich VV, Psakhie SG, Chernykh EN, Shilko EV, Levina EA, Dimaki AV (2018) Baikal ice cover as a representative block medium for research in lithospheric geodynamics. Phys Mesomech 21:223-233. https://doi.org/10.1134/S1029959918030062

9. Vakhromeev AG, Ivanishin VM, Sverkunov SA, Polyakov VN, Razyapov RK (2019) Deep well as a facility for on-line hydraulic studies of the stress state of the rock mass in fluid-saturated fractured reservoirs. Geodyn Tectonophys 10(3):761-778. https://doi.org/10.5800/GT-201910-3-0440

10. Pang X-Q, Jia C-Z, Wanf W-Y (2015) Petroleum geology features and research developments of hydrocarbon accumulation in deep petroliferous basins. Petrol Sci 12:1-53. https://doi.org/ 10.1007/s12182-015-0014-0

11. McGarr A (2012) Relating stick-slip friction experiments to earthquake source parameters. Geophys Res Lett 39:L05303. https://doi.org/10.1029/2011GL050327 
12. Mclaskey GC, Yamashita F (2017) Slow and fast ruptures on a laboratory fault controlled by loading characteristics. J Geophys Res Solid Earth 122:3719-3738. https://doi.org/10.1002/ 2016JB013681

13. Popov VL (2010) Contact mechanics and friction. Physical principles and applications. Springer-Verlag Berlin Heidelberg, Berlin

14. Ruzhich VV, Kocharyan GG (2017) On the structure and formation of earthquake sources in the faults located in the subsurface and deep levels of the crust. Part I. Subsurface level. Geodyn Tectonophys 8(4):1021-1034. https://doi.org/10.5800/GT-2017-8-4-0330

15. Nielsen $S$ (2017) From slow to fast faulting: recent challenges in earthquake fault mechanics. Philos Trans R Soc A Math Phys Eng Sci 375(2103):20160016. https://doi.org/10.1098/rsta. 2016.0016

16. Zhurkov SN (1984) Kinetic concept of the strength of solids. Int J Fract 26:295-307. https:// doi.org/10.1007/BF0096296.1

17. Petrov YuV, Karihaloo BL, Bratov VV, Bragov AM (2012) Multi-scale dynamic fracture model for quasi-brittle materials. Int J Eng Sci 61:3-9. https://doi.org/10.1016/j.ijengsci.2012.06.004

18. Filippov AE, Popov VL, Psakhie SG, Shilko EV (2006) Converting displacement dynamics into creep in block media. Tech Phys Lett 32:545-549. https://doi.org/10.1134/S10637850060 60290

19. Scuderi MM, Collettini C (2016) The role of fluid pressure in induced vs. triggered seismicity: insights from rock deformation experiments on carbonates. Sci Rep 6:24852. https://doi.org/ $10.1038 /$ srep24852

20. Cornelio C, Spagnuolo E, Di Toro G, Nielsen S, Violay M (2019) Mechanical behaviour of fluid-lubricated faults. Nat Commun 10:1274. https://doi.org/10.1038/s41467-019-09293-9

21. Loreto MF, Düşünür-Doğan D, Üner S, İşcan-Alp Y, Ocakoğlu N, Cocchi L, Muccini F, Giordano P, Ligi M (2019) Fault-controlled deep hydrothermal flow in a back-arc tectonic setting, SE Tyrrhenian Sea. Sci Rep 9:17724. https://doi.org/10.1038/s41598-019-53696-z

22. Ruzhich VV, Kocharyan GG, Travin AV, Saveleva VB, Ostapchuk AA, Rasskazov SV, Yasnygina TA, Yudin DS (2018) Determination of the PT conditions that accompanied a seismogenic slip along a deep segment of the marginal suture of the Siberian Craton. Dokl Earth Sci 481:1017-1020. https://doi.org/10.1134/S1028334X18080081

23. Sobolev GA, Vettegren' VI, Ruzhich VV, Ivanova LA, Mamalimov RI, Shcherbakov IP (2015) A study of nanocrystals and the glide-plane mechanism. J Volcanol Seismol 9:151-161. https:// doi.org/10.1134/S0742046315030057

24. Vettegren VI, Ponomarev AV, Sobolev GA, Shcherbakov IP, Mamalimov RI, Kulik VB, Patonin AV (2017) Structural changes in the surface of a heterogeneous nanocrystalline body (sandstone) under the friction. Phys Solid State 59:588-593. https://doi.org/10.1134/S10637834170 30313

25. Medvedev VY, Ivanova LA, Lysov BA, Ruzhich VV, Marchuk MV (2014) Experimental study of decompression, permeability and healing of silicate rocks in fault zones. Geodyn Tectonophys 5(4):905-917. https://doi.org/10.5800/GT-2014-5-4-0162

26. Ruzhich VV, Kocharyan GG, Saveleva VB, Travin A (2018) On the structure and formation of earthquake sources in the faults located in the subsurface and deep levels of the crust. Part II. Deep level. Geodyn Tectonophys 9(3):1039-1061. https://doi.org/10.5800/GT-2018-9-3-0383

27. Ruzhich VV, Truskov VA, Chernykh EN, Smekalin OP (1999) Neotectonic movements in fault zones of the Baikal region and their origin mecha-nisms. Russ Geol Geophys 40(3):356-368

28. Astafurov SV, Shilko EV, Psakhie SG, Rhuzich VV (2008) Effect of local stress on the interface response to dynamic loading in faulted crust. Russ Geol Geophys 49(1):52-58. https://doi.org/ 10.1016/j.rgg.2007.12.007

29. Psakhie SG, Popov VL, Shilko EV et al (2006) A method for controlling the displacement mode in fragments of seismically active tectonic faults. RF Patent 2273035, 27 Mar 2006

30. Bürgmann R (2018) The geophysics, geology and mechanics of slow fault slip. Earth Planet Sci Lett 495:112-134. https://doi.org/10.1016/j.eps1.2018.04.062

31. Michel S, Gualandi A, Avouac J-P (2019) Similar scaling laws for earthquakes and Cascadia slow-slip events. Nature 574:522-526. https://doi.org/10.1038/s41586-019-1673-6 
32. Ostapchuk AA, Pavlov DV, Ruzhich VV, Gubanova AE (2019) Seismic-acoustics of a block sliding along a fault. Pure Appl Geophys. https://doi.org/10.1007/s00024-019-02375-1

33. Rebinder PA, Shchukin ED (1973) The surface phenomena in solids during the course of their deformation and failure. Soviet Physics Uspeki 15(5):533-554

34. Traskin VYu (2009) Rehbinder effect in tectonophysics. Izv Phys Solid Earth 45:952. https:// doi.org/10.1134/S1069351309110032

35. Vakhromeev AG, Sizykh VI (2006) The role of nappe tectonics in the development of abnormally high formation pressure and economic metalliferous brines: a case study of the southern Siberian craton. Dokl Earth Sci 407:209-212. https://doi.org/10.1134/S1028334X06020115

36. Vakhromeev AG, Sverkunov SA, Ivanishin VM, Razyapov RK, Danilova EM (2017) Geodynamic aspects in the study of complex mining and geological conditions for drilling into oiland-gas reservoirs in the riphean carbonate rocks: an overview of the problem as exemplified by the deposits in the Baikit petroliferous district. Geodyn Tectonophys 8(4):903-921. https:// doi.org/10.5800/GT-2017-8-4-0323

37. Vakhromeev AG, Sverkunov SA, Siraev RU, Razyapov RK, Sotnikov AK, Chernokalov KA (2016) The primary method of drilling a horizontal hole in a fracture type of oil and gas saturated carbonate reservoir under conditions of abnormally low reservoir pressure. RF Patent 2602437, 20 Nov 2016, Bull. No. 32 (in Russian)

38. Ruzhich VV, Psakhie SG, Shilko EV, Vakhromeev AG, Levina EA (2018) On the possibility of development of the technology for managing seismotectonic displacements in fault zones. AIP Conf Proc 2051:020261. https://doi.org/10.1063/1.5083504

39. Ma T, Chen P, Zhao J (2016) Overview on vertical and directional drilling technologies for the exploration and exploitation of deep petroleum resources. Geomech Geophys Geo-Energy and Geo-Resour 2:365-395. https://doi.org/10.1007/s40948-016-0038-y

40. Rodkin MV, Rundquist DV (2017) Geofluidogeodynamics. Application to seismology, tectonics, and processes of ore and oil genesis. Publishing House "Intellect", Dolgoprudny (RU)

41. Popov VL, Grzemba B, Starcevic J, Popov M (2012) Rate and state dependent friction laws and the prediction of earthquakes: what can we learn from laboratory models? Tectonophysics 532-535:291-300. https://doi.org/10.1016/j.tecto.2012.02.020

42. Kocharyan GG, Novikov VA (2016) Experimental study of different modes of block sliding along interface. Part 1. Laboratory experiments. Phys Mesomech 19:189-199. https://doi.org/ $10.1134 / \mathrm{S} 1029959916020120$

43. Sibson RH (1973) Interactions between temperature and pore fluid pressure during an earthquake faulting and a mechanism for partial or total stress relief. Nat Phys Sci 243:66-68. https:// doi.org/10.1038/physci243066a0

44. Bachmann CE, Wiemer S, Woessner J, Hainzl S (2011) Statistical analysis of the induced Basel 2006 earthquake sequence: introducing a probability-based monitoring approach for Enhanced Geothermal Systems. Geophys J Int 186(2):793-807. https://doi.org/10.1111/j.1365246x.2011.05068.x

45. Guglielmi Y, Cappa F, Avouac J-P, Henry P, Elsworth D (2015) Seismicity triggered by fluid injection-induced aseismic slip. Science 348(6240):1224-1226. https://doi.org/10.1126/ science.aab0476

46. Weingarten M, Ge S, Godt JW, Bekins BA, Rubinstein JL (2015) High-rate injection is associated with increase in U.S. mid-continent seismicity. Science 348(6241):1336-1340. https:// doi.org/10.1126/science.aab1345

47. Rutqvist J, Rinaldi AP, Cappa F, Jeanne P, Mazzoldi A, Urpi L, Guglielmi Y, Vilarrasa V (2016) Fault activation and induced seismicity in geologic carbon storage-lessons learned from recent modeling studies. J Rock Mech Geotech Eng 8(6):789-804. https://doi.org/10. 1016/j.jrmge.2016.09.001

48. Rinaldi AP, Rutqvist J, Cappa F (2014) Geomechanical effects on $\mathrm{CO}_{2}$ leakage through fault zones during large-scale underground injection. Int J Greenhouse Gas Control 20:117-131. https://doi.org/10.1016/j.ijggc.2013.11.001 
49. Tarasov NT, Tarasova NV (1995) Earthquakes induced by underground nuclear explosions. Environmental and ecological problems. NATO ASI Series (2. Environment), vol 4. SpringerVerlag Berlin, Heidelberg, Berlin, pp 215-223 (Response of seismoactive medium to nuclear explosions)

50. Emanov AF, Emanov AA, Fateev AV, Leskova EV, Shevkunova EV, Podkorytova VG (2014) Mining-induced seismicity at open pit mines in Kuzbass (Bachatsky earthquake on June 18, 2013). J Min Sci 50:224-228. https://doi.org/10.1134/S1062739114020033

51. Mirzoev K, Nikolaev AV, Lukk AA, Yunga SL (2009) Induced seismicity and the possibilities of controlled relaxation of tectonic stresses in the earth's crust. Izv Phys Solid Earth 45:885-904. https://doi.org/10.1134/S1069351309100061

Open Access This chapter is licensed under the terms of the Creative Commons Attribution 4.0 International License (http://creativecommons.org/licenses/by/4.0/), which permits use, sharing, adaptation, distribution and reproduction in any medium or format, as long as you give appropriate credit to the original author(s) and the source, provide a link to the Creative Commons license and indicate if changes were made.

The images or other third party material in this chapter are included in the chapter's Creative Commons license, unless indicated otherwise in a credit line to the material. If material is not included in the chapter's Creative Commons license and your intended use is not permitted by statutory regulation or exceeds the permitted use, you will need to obtain permission directly from the copyright holder.

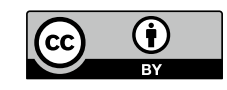

